\title{
BUS LOCATION AND ROUTE SYSTEM USING INTERNET OF THINGS
}

\author{
AMEY VINAYAK RUIKAR, VISWANATHAN V* \\ School of Computing Science and Engineering, VIT University, Chennai Campus, Chennai, Tamil Nadu, India. Email: viswanathan.v@vit.ac.in \\ Received: 23 January 2017, Revised and Accepted: 03 March 2017

\begin{abstract}
The fundamental point of undertaking is to plan a remote correspondence based transport position checking framework which is much helpful in operation. It is imperative to diminish traveler holding up time at transport stop, when clean time dining areas are obscure to traveler or traveler new in the city. To conquer the issue of travelers, the transport area and course route framework have the capacity effortlessly recover data about transport. Global positioning system, additionally furnishing clients with the most limited strolling course to closest bus stop.
\end{abstract}

Keywords: Global positioning system, Bus stop, Transport.

(C) 2017 The Authors. Published by Innovare Academic Sciences Pvt Ltd. This is an open access article under the CC BY license (http://creativecommons. org/licenses/by/4. 0/) DOI: http://dx.doi.org/10.22159/ajpcr.2017.v10s1.19590

\section{INTRODUCTION}

The principle point of the paper is to reduce the holdup time of the travelers and to inform the live upcoming buses timetables of any city transportation with making use of internet of things (IoT). It is imperative to decrease traveler holding up time at city transportation stops, when transportation is running with its full capacity. So as to achieve this, we put forward a city transport area and course route framework by utilizing cell phones. The framework is ready to effectively recover data about transport areas by global position system (GPS), additionally providing clients with the most limited strolling course to the closest transport stops. With a specific end goal to moderate waiting time at city bus stops, travelers would need to acquire live timetables for any city transport stop. To accomplish this confused task, we are proposing the theory for framework, in which IoT is used effectively. The framework transfers information about the present area of a city transport to the smartphone client (traveler). All things considered, even without knowing the whole timetable, the framework empowers the clients to onboard transportation effectively by demonstrating the present area data of a Bus progressively. By utilizing this framework, we can expect a change of client comfort particularly for bus lines that have long operational interims. For effortlessness reason, rather than getting the area information from the bus straightforwardly, we introduce a cell phone in the bus. The framework can then effectively gather the city bus area information by executing the program from the advanced cell phone in the city bus. The application transfers information to the data accumulation (Server 1), which gives provision to stores gathered data in a database. Data conveyance (Server 2) conveys the data to the client, so travelers can get upcoming bus data by getting to a website page produced taking into account the putaway data. Two applications have produced for proposed framework; the first application is intended to gather area information of the bus and second application is showcases area data to clients.

The historical backdrop of route is as old as mankind's history, although early route was restricted to taking after milestones also, remembering courses. Chronicled records demonstrate that the most punctual vehicle route goes back to the development of the south-directing carriage in China around 2600 B.C well-known route gadgets that were widely utilized in right on time route are the smart compass and the odometer. The $17^{\text {th }}$ century disclosure of chronometer by John Harrison provided accurate local time at sea, which helped in tackling the long-known issue of assessing longitudes [1].
The utilization of route gadgets in cars started in the mid- $20^{\text {th }}$ century. Numerous cutting edge cars are furnished with gadgets that are equipped for deciding the present area and afterward powerfully showing and redesigning the present position on computerized guides. Throughout the hundreds of years, different sorts of advances have been strove for route. The revelation of worldwide situating frameworks (GPS) has changed the substance of current route for eternity. The positional precision of non-military personnel GPS recipients has been enhanced to $10 \mathrm{~m}$. Sub-meter precision can additionally be gotten through differential GPS. Route inside bound spaces - for example, transports, structures - can be accomplished through indoor area detecting gadgets [2]. The capacity to precisely decide the position of moving items offered ascend to new administrations known as area based administrations. LBS use precise and continuous situating frameworks and GIS to decide the area of a moving article. The data produced by these frameworks is touchy to the present position of the client and can be utilized to exhort clients about current conditions, for example, climate and activity [3]. Numerous countries are creating at a velocity surpassing light yet one thing that is preventing their improvement is debasement. Payoff is one of them you are always being plundered of your cash. Since we have extraordinary headway in innovation, we ought to utilize it against debasement. As we are moving toward advanced mobile phones, they can be utilized as compelling weapons. A straightforward voice acknowledgment framework alongside an easy stable recorder in our telephones can be a compelling instrument that can be utilized against individuals who request favors for your needs and their obligations. This application can be utilized broadly to check reward taking that is going on surrounding you with no additional expenses exacted by the casualty $[1,4]$. Bitcoin is exploratory, decentralized computerized cash that empowers moment installments to anybody, anyplace on the planet. Bitcoins use shared innovation to work with no focal power. Wallet is the spot where bitcoins are put away. Once bitcoins wallet is introduced on a PC or cellular telephone, it will produce beginning bitcoins location and after that the client can make a location for every exchange [5]. Half-breed cloud offers little business clients the adaptability of a cloud-based arrangement with the security of a locally housed server. The client's information is put away on the New Hybrid Cloud Server, and the New Hybrid Cloud Server is situated at the client's site, however, is overseen remotely. A style of figuring where greatly versatile (and flexible) IT-related capacities for other clients to manage with utilizing internet. Robotization of New Hybrid Cloud is vital to distinguish the deformities and to correct them ahead of schedule before the item is discharged. 
The customary manual method for approval is tedious and additionally expends labor. Robotization of Hybrid Cloud helps in sparing assets furthermore helps in porting New Hybrid Cloud on different stages with changing structural engineering and elements [6].

In the rest of paper, the contents are as follow:

Section 2 is for background, in that which technology we have used is given. In section 3 , the related work is given. In section 4 , the methodology of this paper is defined. Section 5 the proposed system is explained. And at last section, conclusion of this paper is given.

\section{BACKGROUND USED THE JAVA PLATFORM}

A stage is the equipment or programing environment in which a project runs. The Java stage varies from most different stages in that it's a product just stage that keeps running on top of other, equipment based stages. In general, other stages are depicted as a blend of equipment and working framework.

The Java stage has two segments; first one is Java Virtual Machine and the Java Application Programming Interface (Java API).

The Java API is an expansive accumulation of instant programming segments that give numerous helpful abilities, for example, graphical client interface widget. The Java API is assembled into libraries (bundles) of related segment.

\section{Hypertext pre-processor (PHP)}

PHP innovation empowers Web engineers and originators to quickly create and effortlessly keep up, data rich, element Web pages that influence existing business frameworks. As a major aspect of the Microsoft innovation family, PHP innovation empowers quick advancement of Web-based applications that are stage autonomous.

\section{GPS}

The USDepartment of defense is controlling the GPS, formed by 24 satellites circling around earth in star formation. GPS decides the gadgets position by ascertaining contrasts in the time's signals from diverse satellites take to achieve the collector as shown in Fig. 1. GPS signs are encoded, so the cell phone must be outfitted with a GPS beneficiary. GPS is conceivably the most precise technique (somewhere around 4 and 40 meters if the GPS recipient has an unmistakable perspective of the sky); however, it has a few disadvantages: The additional equipment can be unreasonable, expends battery while being used, and requires some warm-up after a cool begin to get an introductory fix on noticeable satellites.

\section{Working of GPS}

The standard behind GPS is the estimation of separation (or "Reach") between the satellites and the collector. The satellites let us know precisely where they are in their circles by television information the collector uses to figure their positions. It works something like this: If we know our accurate separation from a satellite in space, we know, we are some place on the surface of a fanciful circle with a sweep equivalent to the separation to the satellite range.

\section{Google APIs}

Google APIs are an arrangement of JavaScript APIs created by Google that permits association with Google Services and joining of rich, media, inquiry or feed based Internet content into web applications. They broadly utilize AJAX scripting and can be effectively stacked utilizing Google Loader.

\section{Android}

Google developed Android operating system which is based on the Linux kernel and designed first and foremost for touchscreen mobile devices such as smartphones and tablet. Android is a thorough stage, which implies it is a finished programing stack for a cell phone. For designers, Android gives every one of the instruments and systems for creating portable applications rapidly and effectively. Instated of physical smartphone to develop an android application you can begin with the android emulator.

\section{RELATED WORK}

Numerous transportation associations have proposed intelligent transport framework for the comfort of clients to diminish holding up time of travelers.

Lin et al. [7] suggested an arrangement of transport arrival time forecast calculations for a travel information system framework executed in Blacksburg, Virginia. Four calculations were presented with various assumptions on input information and were perform better than a few calculations from the literature. Their calculations, be that as it may, did not consider the impact of traffic congestion and abide time at transport stations. Kidwell [8] presented a calculation for anticipating transport arrival times in light of real-time vehicle area. The algorithm worked by separating every route into zones and recording the time that every transport went through every zone. Forecasts depended on the latest perception of transport going through every zone. This algorithm could not work in large cities where both travel time and dwell time could be subject to large variations.

\section{Public transportation with GPS tracking}

The Transit Smart Card System known as Automated Fare Collection System gives us a superiority over the manual toll accumulation framework by bringing down work costs furthermore expanding the productivity of manual process of fare gathering. The longing to concentrate more data than only a basic finding of admission from travel brilliant cards has prompted the examination endeavors in relevant other significant data, for example, purposes of inception where a traveler would board a transport and have the information recorded as the traveler's smart card is checked. A Markov chain based

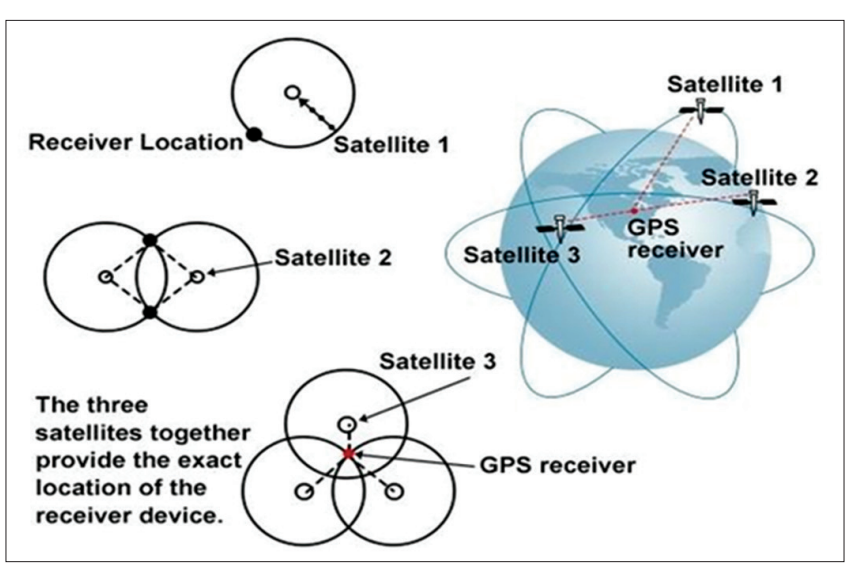

Fig. 1: Working of global position system

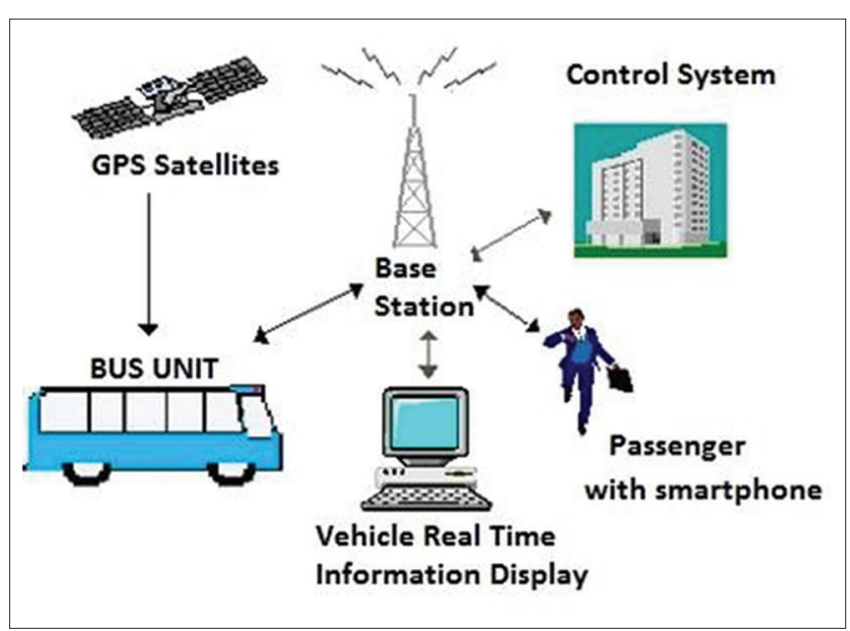

Fig. 2: Architecture of proposed system 
Bayesian decision tree algorithm has been developed to achieve the above aim. In this study, wherein the calculation is confirmed with the utilization of open transportation vehicles that are equipped with GPS following and information loggers. Overwhelmingly, it is expressed that information gathered to represent the purposes of inception when a traveler's travel smart card is checked, is crucial to the procedure of travel framework arranging [6]. In one more research, the GPS technology is being applied toward tracking and scheduling of buses. This has been executed in Ahmedabad India, where the government has set up a GPS-enabled bus rapid transit system (BRTS) to way out their issues of transportation in a sustainable manner. Presentation of the BRTS was inspired by the requirement for expanded unwavering quality and security with prime concentrate on decreasing travel time. The control center is precisely tracking and scheduling of all buses on all routes of transportation [9].

\section{Public transportation with radio frequency identification (RFID)} for scheduling

RFID technology consists of mainly three components: RFID tag, RFID Reader, and Middleware logic for communication with the back-end database uninterruptedly. In the past few years, a lot of applications for RFID technology have been proposed and developed. However, these determinations have been confronted with regard to their practicability, utilization, confidentiality, safety, and such other features. One of such researches is centered on using RFID toward potential travelers going through a reenacted transport entryway outfitted with business offthe-rack RFID reader and radio wires, travelers as they board and leave the transport. The examination reasoned that RFID innovation can be successfully utilized for this sort of utilization; be that as it may, there was a problem which troubled the idea. As per the radiation pattern and situating of antenna, it was identified that in the event of no observable pathway between smart cards and reader; there may be some execution bugs as these variables are exceptionally significant as well as basic to the entire procedure of acknowledgment [10]. Research was additionally centered around how RFID technology can be utilized to fathom inconvenience confronted by Public Transport Authorities particularly in metropolitan urban communities by doing research for upgrade of mechanized following of transports that can be exceptionally valuable in giving helpful appraisals with respect to transport entry times and thusly give enhanced traveler comfort. A continuous following and checking framework are utilized which uses a structure of event, condition and action. This ends up being useful in separating information successful to expel all the undesirable or incorrect subtle elements and afterward arrange helpful information by grouping. Use of gathered information for the expectation of transport development is likewise talked about with an end goal to enhance the following framework and thus upgrade voyaging background by Public Transport [11].

\section{Methodologies based on hardware}

To solve the problem of bus tracking and scheduling lot of hardware based approaches have been suggested. Almost all of the approaches practice the same basic architecture: Microcontroller, GPS module, GPRS/ global system for mobile (GSM) modem. All above elements are bundled together to shape an On-Board Unit which is installed onto the transport. The GPS gathers area information which is directed to the small scale controller which thus guides it to the GPRS/GSM modem, transmitting information through remote cellular system to the back-end server. Arranging all the potential information and removing significant data from GSM modem like dynamic route tracking is done by the back-end server.. The proposed architecture is represented in the form of picture, as seen in the Fig. 2. Pham et al. [12] propose a unique vehicle tracking method with the use of GPS module, which is utilized to acquire the vehicle's coordinate. On the other hand, the GSM modem is applied to transmit the location to the client's telephone using the network. In the world of computerized cellular mobile network GSM Communications brought revolutionary second-era [13]. It is broadly set out all over the place in world. Even though enhancements to GSM such as the next generation systems have been set rolling out to satisfy for faster data centric traffic, backward compatibility to GSM is still retained. Because of its extensive accessibility, it is picked as the intermediate for exchange of area data. The straightforward and reasonable short message service (SMS) permits clients to send up to 160 characters. With the end goal of this venture, the SMS is more than adequate for sending the area data. The cutting edge module u-blox NEO-6Q GPS receiver and u-blox LEON-G 100 GSM is utilized by Pham et al. [12] in their hardware implementation. To control both modules with better enhancement a microcontroller, the Arduino [14] is additionally utilized and to give an effortlessly adaptable stage to any prerequisite application. Further smaller scale controllers, such as Raspberry Pi [14] and Arduino Mega, are likewise being utilized for the improvement of tracking applications designed for vehicle on an extensive measure. These sheets give a simple easy to use advancement environment to make viable applications in a straightforward way.

Table 1: Basic self-starting vehicle location technology information

\begin{tabular}{|c|c|c|c|c|}
\hline Agency & $\begin{array}{l}\text { AVL equipped } \\
\text { vehicles }\end{array}$ & $\begin{array}{l}\text { Total number } \\
\text { of vehicles }\end{array}$ & Type of AVL & $\begin{array}{l}\text { Frequency of location } \\
\text { update (in min) }\end{array}$ \\
\hline City bus (Williamsport, Penn.) & 25 & 25 & GPS & 5.0 \\
\hline DTC & 189 & 189 & GPS & 1.0 \\
\hline Fairfax saver (CUE) (Fairfax, Va.) & 12 & 12 & GPS & 0.5 \\
\hline Glendale Beeline (Glendale, California) & 20 & 35 & GPS & 1.5 or every $200 \mathrm{~m}$ \\
\hline King County Metro & 1300 & 1300 & Sign post & 1.0 to 3.0 \\
\hline LACMTA & 150 & 150 & $\begin{array}{l}\text { Transponder to } \\
\text { inductive loop system }\end{array}$ & 1.0 \\
\hline RTD & 1111 & 1111 & GPS & 2.0 \\
\hline San Francisco Muni (San Francisco, California) & 827 & 827 & GPS & 1.5 \\
\hline Tri-County Metropolitan Transportation Oregon (Tri-Met) & 689 & 689 & GPS & $1.33-1.5$ \\
\hline ATC Bologna (Bologna, Italy) & 450 & 976 & GPS & 0.5 \\
\hline Centro (Birmingham, U.K.) & 6 & NR & GPS & 0.5 \\
\hline Dublin Bus (Dublin, Ireland) & 156 & 1062 & GPS & 0.5 \\
\hline Kaohsiung (Taiwan) & 250 & 500 & GPS & 0.5 \\
\hline Taichung (Taiwan) & 250 & 480 & GPS & 0.5 \\
\hline Kent County Council (Kent, U.K.) & 141 & 700 & DGPS & 0.5 \\
\hline London Bus Services Limited (London Buses) (London, U.K.) & 5700 & 6600 & Signpost & 0.5 \\
\hline YTV (Helsinki Metropolitan Area Council) (Helsinki, Finland) & 340 & 550 & DGPS and Signpost & 0.5 \\
\hline
\end{tabular}

DTC: Delaware Transit Corporation, GPS: Global position system, RTD: Regional Transportation District, LACMTA: Los Angeles County Metropolitan Transportation Authority, CUE: City-University-Energy 
Tabular form of basic self-starting vehicle location technology information (Table 1) for each corresponding agency, the number of vehicle connects with AVL system. Furthermore, this table explains the most reacting transportation companies are using either GPS or DGPS- based AVL technology, which gives a better location on GPS.

\section{METHODOLOGY}

The GPS fitted into a vehicle as a major aspect of the vehicle-mounted unit in the transit will get the longitude also, scope facilitates from the Satellite. These data are then sent crosswise over to the Central Control Station through the remote correspondence connection, for example, GSM/GPRS. The application at the Central control station on getting the position inputs will redesign the showcase sheets at the transport covers and the transport terminal stage presentation board. Furthermore, the general showcase board at the related transport terminals. They have utilized the accompanying showcase sheets for giving data to the clients.

\section{PROPOSED SYSTEM}

Keeping in mind the end goal to lessen holding up time at city bus stops, travelers would need to get live timetables for any city transport stop to accomplish this confounded assignment; we propose another city bus area and course route framework by utilizing IoT. The framework transfers information about the present area of a city bus to the smartphone client (traveler). In that capacity, even without knowing the whole timetable, the framework empowers the clients to get on a city bus effortlessly by demonstrating the present area data of a bus continuously. By utilizing this framework, we can expect a change of client accommodation particularly for bus lines that have long operational interims.

For straightforwardness reason, rather than getting the area information from the bus specifically, we introduce a smartphone in the transport. The application transfers information to the data gathering (Server 1), which stores gathered data in a database. Data conveyance (Server 2) conveys the data to the client, so travelers can get current bus data by getting to a site page created in light of the putaway data. We have created two applications for our proposed framework.

i. First application is intended to gather area information of the bus.

ii. The second application shows area data to clients.

To predicting the next possible node, we are using the A start $\left(\mathrm{A}^{*}\right)$ algorithm. In computer science, $A^{*}$ is a computer algorithm that is widely used in route finding and graph traversal, the process of plotting an efficiently traversable path between multiple points, called nodes [15].

$A^{*}$ algorithm is an informed search algorithm which uses the heuristic function to find out the next node which should be considered in the tree traversal [13].

\section{CONCLUSION}

This paper furnishes travelers with data, for example, most limited strolling course to the adjacent transport stops, separation and heading to the adjacent transport stops, accessible transports, transport courses, and inexact entry time of the transports. We create a framework that recovers the transport area utilizing GPS which represents precision in finding the present area of the transport. The upsides of the proposed framework is that it gives continuous redesigned data, decreases traveler holding uptime, utilization of android telephones empowers simplicity of use and is easy to use furthermore the framework has low usage and upkeep cost.

\section{REFERENCES}

1. Chandurkar S, Mugade S, Sinha S, Misal M, Borekar P. Implementation of real time bus monitoring and passenger information system. Int J Sci Res Publ 2013;3(5):4.

2. Available from: https://www.en.wikipedia.org/wiki/Android_(operating system).

3. Available from: http://www.developer.android.com.

4. Ravi P, Rohitaksha K, Abhilash CB, Pradeep HK. An innovative approach for city bus location with route navigation system using android. Eur J Adv Eng Technol 2015;2(3):38-45.

5. de Cáceres M, Andrés MO, del Olmo SH, Jiménez RC. Real time passenger information systems and quality of bus services. Transp Telecomm J 2012;14(2):155-66.

6. Xiao-lei MA, Yin-hai WA, Feng CH, Jian-feng LI. Transit smart card data mining for passenger origin information extraction. J Zhejiang Univ Sci C 2012;13(10):750-60.

7. Lin WH, Zeng J. Experimental study of real-time bus arrival time prediction with GPS data. Transp Res Rec J Transp Res Board 1999;1666:101-9.

8. Kidwell B. Predicting Transit Vehicle Arrival Times. Bridgewater, Mass: Geo Graphics Laboratory, Bridgewater State College; 2001.

9. Dave S, Harter G, Sharma A, Sinha J. Sustainable Urbanization: The Role of ICT in City Development. Booz \& Company Inc.; 2010. Available from: http://www.booz.com/media/uploads/Sustainable_ Urbanization.pdf.

10. Christian O, Torres-Torriti M, Landau D. Performance evaluation of UHF RFID technologies for real-time passenger recognition in intelligent public transportation systems. IEEE Trans Intell Transp Syst 2010;11(3):748-53.

11. Menezes B, Laddhad K, Kresit KB, Dutta K. Challenges in RFID Deployment - A Case Study in Public Transportation. ICEG 2006: The $4^{\text {th }}$ International Conference on E-Governance, New Delhi, India. Vol. 1; 2006.

12. Pham, HD, Drieberg M, Nguyen CC. Development of Vehicle Tracking System Using GPS and GSM Modem. Open Systems (ICOS), 2013 IEEE Conference on. IEEE; 2013.

13. El-Rabbany A. Introduction to GPS: The Global Positioning System. Norwood, MA: Artech House; 2002.

14. Arduino. Arduino: Main Page; 2013. Available from: http://www. arduino.cc.

15. Available from: https://www.en.wikipedia.org/wiki/A_search_algorithm. 